\title{
Health-Related Quality of Life of European Children and Adolescents with Short Stature as Assessed with Generic (KIDSCREEN) and Chronic-Generic (DISABKIDS) Instruments
}

\author{
Neuza Silva ${ }^{1,2}$, Monika Bullinger ${ }^{1}$, Julia Quitmann ${ }^{1}$, Ulrike Ravens-Sieberer ${ }^{3}$, Anja \\ Rohenkohl ${ }^{1}$, and the QoLISSY Group
}

\footnotetext{
${ }^{1}$ University Medical Centre Hamburg-Eppendorf, Department of Medical Psychology, Martinistraße 52 W26, 20246 Hamburg, Germany

${ }^{2}$ University of Coimbra, Faculty of Psychology and Education Sciences, Rua do Colégio Novo, Apartado 6153, 3001-802 Coimbra, Portugal

${ }^{3}$ University Medical Centre Hamburg-Eppendorf, Department of Child and Adolescent Psychiatry and Psychotherapy, Martinistraße 52 W29, 20246 Hamburg, Germany
}

\begin{abstract}
Introduction. Short stature may be associated with impairments in health-related quality of life (HrQoL). This study compares the HrQoL of children/adolescents diagnosed with short stature to population norms and examined the effects of height deviation and treatment status on HrQoL. Method. We cross-sectionally assessed 110 children/adolescents aged 8-18, with current short stature (height deviation equal to or below -2 $S D$ ) or normal height achieved since diagnosis, and 98 parents, using the generic KIDSCREEN and the chronic-generic DISABKIDS instruments. Results. Generic HrQoL of patients was similar to population norms. Patients with achieved normal height reported better chronic-generic HrQoL when untreated, while patients with current short stature reported better HrQoL when receiving treatment. Parents reported better HrQoL for treated patients, especially for girls. Conclusion. Although their HrQoL is not significantly compromised, patients diagnosed with short stature may profit from growth-hormone treatment. Specific instruments are needed to adequately assess the effectiveness of treatment.
\end{abstract}

Keywords: Short stature, children and adolescents, growth-hormone treatment, health-related quality of life, patient- and proxy-reported outcomes.

Silva, N., Bullinger, M., Quitmann, J., Ravens-Sieberer, U., Rohenkohl, A., \& The QoLISSY Group (2013). Health-related quality of life of European children and adolescents with short stature as assessed with generic (KIDSCREEN) and chronic-generic (DISABKIDS) instruments. Expert Review of Pharmacoeconomics \& Outcomes Research, 13(6), 817-827. doi:10.1586/14737167.2013.847366 


\section{Introduction}

The assessment of health related quality of life (HrQoL) is considered an important issue in medical research and clinical practice. While $\mathrm{HrQoL}$ research in adults has progressed substantially over recent years, research in children and adolescents has lagged behind due to conceptual and methodological challenges [1,2]. According to the World Health Organization (WHO) recommendations, instruments developed to assess HrQoL in paediatric health conditions should include patient self-assessment as well as parent-proxy report, be age appropriated, be applicable in cross-cultural research contexts, and should consider both generic and condition-specific aspects of HrQoL [3]. A unique approach to meet these challenges has been pursued with the generic KIDSCREEN and the chronicgeneric DISABKIDS instruments [4]. These measures were cross-culturally developed and they can be used conjointly to assess child health in epidemiological and clinical studies in a wide range of health conditions, including paediatric short stature. In this specific condition, HrQoL has been increasingly considered a key outcome, providing insight into potential impact of height on children's well-being and functioning and supporting treatment decision making $[5,6]$.

\section{Short Stature and Growth Hormone Treatment}

On an auxological basis, short stature is defined as a body height more than two standard-deviations $(S D)$ below the population mean for age and gender [7-9]. The aetiology of short stature is associated with genetic, endocrine, environmental (e.g., socioeconomic conditions, nutrition) and psychosocial factors (e.g., psychological stress, emotional deprivation) [10,11]. Among endocrine factors, which represent only 5\% of cases, growth hormone deficiency (GHD) is the most frequent [12]. However, children with sufficient growth hormone $(\mathrm{GH})$ secretion, normal birth size, and no evidence of systemic disease, psychiatric disorders or malnutrition, can also have a height that falls below the population norms [13]. This heterogeneous group which lacks a specific aetiology and includes 60 to $80 \%$ of the short-statured children is classified as idiopathic short stature (ISS) $[9,14]$.

Recombinant human GH (rhGH) treatment by daily subcutaneous injection is the most effective option to increase growth velocity and to normalize adult height in children with GHD [15]. Although children with ISS have normal levels of GH secretion, it may be insufficient to stimulate the GH receptors [16]. A growing body of research has supported the effectiveness of rhGH treatment to improve adult height in children with ISS [17]. However, if catch-up growth is slow or the GH treatment is unsuccessful, the children may remain 
relatively short when compared to same-aged peers and this height disparity could widen over time [17].

\section{Health-related Quality of Life in Children with GHD or ISS}

The impact of short stature in wellbeing and functioning is not only due to environmental barriers to the child's autonomy, but also a result of negative comparisons with peers, expectations of parents or stature-related stereotypes affecting children's selfperception and social integration [6]. Children and adolescents with short stature have been reported to be at increased risk for psychosocial stress due to stigmatization, social isolation, juvenalization, low self-esteem, and being bullied [9,18,19]. However, significant behavioural or mental health clinical problems are not frequent [20] and the current data is neither sufficient nor unequivocal enough to evaluate the impact of short stature on psychosocial adaptation outcomes [6,21]. While some studies have described significant HrQoL impairment and more behavioural, cognitive, emotional and social problems among children and adolescents with GHD or ISS [22,23], other studies have failed to detect differences from population norms $[21,24,25]$.

GH treatment is not only aimed at increasing growth velocity and adult height but also at improving children's wellbeing and functioning. In a longitudinal study, Sheppard and colleagues [22] found an improvement in HrQoL, after 6 months of GH treatment. Even though the effects of GH treatment and induced height gain to improve the HrQoL were not supported in other studies [24-26], there seems to be consensus that patients and parents are satisfied with GH treatment, suggesting that the expectations about adult height surpass the burden of daily treatments and regular medical appointments [24,26-28].

The variability of psychosocial adaptation of children and adolescents with short stature may be a result of a complex interplay between risk and protective factors, including child's characteristics and environmental features [9]. In a literature review, Visser-van Balen and colleagues [28] identified the male gender, lower intelligence, the presence of a younger but taller sibling, being treated as younger than chronological age, and low family socioeconomic status as factors associated with maladjustment. Nevertheless, children's perception of their condition, their self-image and satisfaction with height may influence the way they interact with other people and cope with negative social feedback.

The inconsistent results across studies can also be attributed to methodological issues, namely the sources of information and the measures used to assess health outcomes. Parents of children with short stature tend to rate their children as having lower social functioning, 
poorer self-esteem, and more behavioural and cognitive problems than children with average height, while this view is rarely shared by young patients [6,28]. This limited agreement calls for capturing both patients' and parents' reports in order to better understand the impact of short stature on children's wellbeing and functioning [20].

HrQoL instruments can be divided into generic and condition-specific measures [29]. Most of research in paediatric short stature has employed generic instruments which, on the one hand, are useful tools to access HrQoL across the general population and across health conditions, comparing the impact of health status along the continuum from excellent to poor health, but, on the other hand, they may not detect subtle but clinically relevant differences or changes in HrQoL [30,31]. A recent review identified several measures specifically developed to assess HrQoL in children with short stature [5]. However, little data is available on the psychometric performance of some of these instruments and their applicability to referred patients with GHD or ISS [6]. To bridge the gap between generic and specific instruments, so-called chronic-generic instruments have been developed. This non-categorical approach suggests that nosologically different health conditions may lead to similar impacts on wellbeing and functioning [32]. Chronic-generic measures can be used across different conditions or comorbidities without sacrificing the sensitivity to the disease-related consequences.

\section{Aims and Hypotheses}

The present paper describes the HrQoL of children and adolescents diagnosed with GHD or ISS, from their own perspective (patient-reports) as well as from their parents' perspective (parent-reports), by using the generic KIDSCREEN and the chronic-generic DISABKIDS instruments. Specific objectives were: (1) to compare the generic HrQoL of children/adolescents diagnosed with short stature to the population norm data; (2) to examine the main and interaction effects of height deviation and GH treatment on HrQoL; (3) to identify patients' socio-demographic and clinical variables associated with HrQoL scores; and (4) to inspect the agreement between patients' and parents' ratings of HrQoL.

Based on the current literature, the following hypotheses were formulated. First, we expected lower generic HrQoL among children/adolescents diagnosed with GHD and ISS when compared to the European norms, but yet within the normal range. Second, we hypothesized that treated children/adolescents with achieved normal height would have better HrQoL than untreated children/adolescents with current height deviation equal to or below -2 $S D$. We also anticipated that the chronic-generic instrument would be more sensitive in 
detecting height- and treatment-related differences on $\mathrm{HrQoL}$ as compared to the generic instrument. Third, we predicted that higher HrQoL scores would be positively associated with female gender, younger age, lower height deviation and being treated/ have been treated with rhGH. Finally, we expected moderate agreement between patients' and parents' reports, with parents identifying more HrQoL impairment than children/adolescents themselves.

\section{Methods}

\section{Participants and Procedures}

The present study is part of the Quality of Life in Short Stature Youth (QoLISSY) project, which aimed to critically evaluate the performance of generic and chronic-generic measures, as well as to develop a cross-cultural disease-specific HrQoL measure for children and adolescents with short stature, aged 8 to 18 years-old, as well as for parents of children aged 4 to 18 years-old. The QoLISSY project was conducted in five European countries (France, Germany, Spain, Sweden and United Kingdom) and comprised three phases conducted simultaneously in the five participating countries, namely (A) focus-groups with item generation; (B) pilot test with cognitive debriefing; and (C) field test with re-test with a total of over 1000 patients and parents [35].

The cross-sectional sample for the present study was collected in paediatric endocrine centres of the five countries (France, Germany, Spain, Sweden and UK) within the QoLISSY pilot test phase (B), upon approval by the respective Ethic Committees. For inclusion in the sample, children and adolescents had to meet the following criteria: (1) age between 8 and 18 years-old; (2) clinical diagnosis of GHD or ISS; (3) height equal to or below -2 SD from the norms for their age, gender and nationality, at the time of diagnosis; (4) absence of defined comorbid chronic health conditions; and (5) cognitive ability to understand and complete the questionnaires. One of the parents of the child/adolescent was included, as were parents of children aged 4-7 years (not included in the current analysis). Respecting the 2008 World Medical Association Declaration of Helsinki ethical principles for medical research involving human subjects, detailed information about the study aims and procedures was provided in the respective language when the families attended to the clinical centres for clinical regular appointments. Informed consents were obtained from parents together with assents from children/adolescents, as was permission to extract medical data from the clinical records through their physicians. For the families who agreed to participate, the questionnaires to be 
independently completed by patients and parents were given to families when they visited the clinical centres for the focus groups or cognitive debriefings, or were sent by mail, together with a pre-stamped envelope for returning the completed questionnaires to the respective centre. The data was entered into a project specific SPSS database in each centre, which included the computation of the height deviation at the time of assessment with reference to the national norms for age and gender, and was subsequently sent to the German coordinating centre.

\section{Measures}

The children's and adolescents' generic and chronic-generic HrQoL were respectively assessed by the self- and parent-rated versions of the KIDSCREEN-10 Index [33] and of the DISABKIDS Chronic Generic Measure - short version (DCGM-12) [34]. The KIDSCREEN10 comprises 10 items assessing general subjective health and well-being (e.g., "Have you felt fit and well?"/ "Has your child felt fit and well?"). The DCGM-12 included 10 items measuring the impact of chronic health conditions on quality of life (e.g., "Does your condition get you down?"/ "Does your child's condition get him/ her down?"); and two items measuring the impact of treatments, which were used in GH treated children/adolescents only (e.g., "Does taking medication bother you?"/ "Does taking medication bothers your child?"). Both instruments were answered using a 5-point Likert scale ranging from 1 (never/ not at all) to 5 (always/ extremely) and provided standardized scores (ranging from 0 to 100), with higher scores indicating better HrQoL. In the QoLISSY sample of children/adolescents with short stature, adequate internal consistency values were observed: $\alpha=.81$ and $\alpha=.80$ for generic HrQoL, patient and parent reported respectively; and $\alpha=.92$ for patient-reports and $\alpha$ $=.87$ for parent-reports of chronic-generic HrQoL.

The socio-demographic data was collected from children/adolescents and parents, and clinical data was provided by the child's physician. Although a height deviation equal to or below -2 $S D$ from the norms at the time of diagnosis was required for inclusion in the sample, some children/adolescents had achieved a normal height at the time of assessment due to normal growth or GH treatment. Thus, the current height deviation was categorized into two groups: achieved normal height (height deviation above $-2 S D$ ) and current short stature (height deviation equal to or below -2 SD). Regarding treatment status, the group of treated children/adolescents included those who were receiving rhGH treatment at the time of assessment and those who had received prior treatment; the untreated group included never treated children/adolescents. 


\section{Data Analysis}

The statistical analyses were performed using the Statistical Package for Social Sciences 17.0 (SPSS Inc., Chicago, IL). Except for socio-demographic and clinical variables, missing data were handled by individual mean score allocation, if they were random and less than 5\%. Since this was an exploratory study, results were considered significant at a $90 \%$ confidence interval $(p \leq .10)$. Descriptive statistics were obtained for socio-demographic and clinical variables and the homogeneity of the frequency distribution of the clinical characteristics between patients' age and gender groups was examined using chi-square tests.

To compare the self- and parent-reported generic HrQoL mean scores with the European norms [33], one-sample t-tests were performed, for the total sample and for current height deviation and treatment status groups separately.

Differences between current height deviation (above -2 $S D$ vs. equal to or below -2 $S D$ ) and treatment groups (GH treated vs. untreated) on paediatric generic and chronicgeneric HrQoL were tested with two multivariate analyses of covariance (two-way MANCOVA), one for the patients' reports and another one for the parents' reports. We controlled for the effects of children/adolescents' gender, age group and type of diagnosis by including them as covariates. Because of the small sample size and unequal group sizes, the Pillai's Trace statistic was used to evaluate the significance of multivariate effects, after verifying the assumption of homogeneity of covariance matrices (Field, 2009). When multivariate effects were significant, univariate analyses were performed to examine which dimensions of HrQoL were significantly different between groups. Effect-size measures were presented for the comparison analyses, considering $\mathrm{y}_{\mathrm{p}}{ }^{2} \geq .01 ; \mathrm{y}_{\mathrm{p}}{ }^{2} \geq .06$; and $\mathrm{y}_{\mathrm{p}}{ }^{2} \geq .14$ as small, medium and large effects, respectively [36].

Hierarchical multiple regression analyses were conducted to identify the factors associated with the generic and chronic-generic HrQoL, patient and parent reported, entering the socio-demographic characteristics (gender and age group) in the first block and the clinical variables (diagnosis, height deviation and treatment status) in the second block of the regression equation.

Agreement between patient- and parent-reports was examined at the individual and group levels [37] by using Intraclass Correlation Coefficients (ICC) and Multivariate Analysis of Covariance for repeated measures (MANCOVA) approaches. ICC employed a two-way mixed model with the absolute agreement method. The MANCOVA was performed by entering the informant as within-subject factor, the clinical variables (current height deviation and treatment status) as between-subjects factors, and the socio-demographic 
variables (gender and age groups) as covariates. The differences between the ICC were tested by transforming the correlation coefficients in Fisher $Z$-values [38].

\section{Results}

\section{Sample Characteristics}

One hundred and ten patients, with 55 children aged between 8 and 12 years and 55 adolescents aged between 13 and 18 years, as well as 98 parents have completed both DISABKIDS and KIDSCREEN instruments during the QoLISSY pilot test phase. Sociodemographic and clinical sample characteristics are presented in Table 1. Chi-square tests showed that the clinical and socio-demographic characteristics are similarly distributed between children/adolescents' age and gender groups.

Table 1. Socio-demographic and clinical characteristic of the sample.

\begin{tabular}{|c|c|c|c|c|}
\hline & & $\begin{array}{c}\text { Children } \\
(n=55)\end{array}$ & $\begin{array}{c}\text { Adolescents } \\
(n=55)\end{array}$ & $\begin{array}{l}\text { Parents } \\
(n=98)\end{array}$ \\
\hline \multicolumn{5}{|c|}{ Socio-demographic characteristics } \\
\hline \multirow[t]{3}{*}{ Gender, $n(\%)$} & Male & $33(60 \%)$ & $33(60 \%)$ & $8(8.2 \%)$ \\
\hline & Female & $22(40 \%)$ & $22(40 \%)$ & $64(65.3 \%)$ \\
\hline & Missing & - & - & $26(26.5 \%)$ \\
\hline Age, $M(S D)$ & & $10.58(1.34)$ & $14.10(1.13)$ & $43.67(4.67)$ \\
\hline \multirow[t]{5}{*}{ Country, $n(\%)$} & Sweden & $11(20 \%)$ & $13(23.6 \%)$ & $26(26.5 \%)$ \\
\hline & Germany & $18(32.7 \%)$ & $24(43.6 \%)$ & $42(42.9 \%)$ \\
\hline & France & $9(16.4 \%)$ & $4(7.3 \%)$ & - \\
\hline & Spain & $13(23.6 \%)$ & $12(21.8 \%)$ & $25(25.5 \%)$ \\
\hline & UK & $4(7.3 \%)$ & $2(3.6 \%)$ & $5(5.1 \%)$ \\
\hline \multicolumn{5}{|c|}{ Clinical characteristics } \\
\hline \multirow[t]{3}{*}{ Diagnosis, $n(\%)$} & GHD & $28(50.9 \%)$ & $31(56.4 \%)$ & - \\
\hline & ISS & $26(47.3 \%)$ & $22(40 \%)$ & \\
\hline & Missing & $1(1.8 \%)$ & $2(3.6 \%)$ & \\
\hline \multirow{3}{*}{$\begin{array}{l}\text { Current height } \\
\text { deviation, } n(\%)\end{array}$} & Above $-2 S D$ & $22(40 \%)$ & $26(47.3 \%)$ & - \\
\hline & Equal or below $-2 S D$ & $22(40 \%)$ & $18(32.7 \%)$ & \\
\hline & Missing & $11(20 \%)$ & $11(20 \%)$ & \\
\hline \multirow[t]{3}{*}{ GH treatment, $n(\%)$} & Treated & $33(60 \%)$ & $33(60 \%)$ & - \\
\hline & Untreated & $15(27.3 \%)$ & $16(29.1 \%)$ & \\
\hline & Missing & $7(12.7 \%)$ & $6(10.9 \%)$ & \\
\hline
\end{tabular}




\section{Generic HrQoL in Children/Adolescents with Short Stature and Norm Data}

The generic HrQoL standardized mean scores were compared with the European KIDSCREEN norms $[M(S D)=74.07$ (14.94) for patient-reports and $M(S D)=74.88(12.03)$ for parent-reports] [33]. As displayed in Table 2, in the total sample, children/adolescents with short stature tended to report better HrQoL as compared to population norms. Further analyses by current height deviation and treatment status indicated that the differences were only significant for children/adolescents who were receiving/ have received GH treatment. For parent-reported HrQoL, no significant differences were found between parents of children/adolescents with short stature and parents from the normal population.

Table 2. Comparison of generic $\mathrm{HrQoL}$ between patients diagnosed with short stature and population norms.

\begin{tabular}{llcccccccc}
\hline & & \multicolumn{4}{c}{ Patient-reports of generic HrQoL } & \multicolumn{5}{c}{ Parent-reports of generic HrQoL } \\
\cline { 2 - 9 } Group & $\boldsymbol{n}$ & $\boldsymbol{M}(\boldsymbol{S D})$ & $\boldsymbol{t}$ & $\boldsymbol{p}$ & $\boldsymbol{n}$ & $\boldsymbol{M}(\boldsymbol{S D})$ & $\boldsymbol{t}$ & $\boldsymbol{p}$ \\
\hline $\begin{array}{l}\text { Current height } \\
\text { deviation above }\end{array}$ & Treated & 39 & $79.17(12.88)$ & 2.47 & .02 & 40 & $73.31(12.65)$ & -.78 & .44 \\
$-2 S D$ & Untreated & 5 & $79.50(12.17)$ & 1.00 & .38 & 5 & $75.00(10.90)$ & .03 & .98 \\
$\begin{array}{l}\text { Current height } \\
\text { deviation equal } \\
\text { to or below - }\end{array}$ & Treated & 20 & $80.63(12.56)$ & 2.33 & .03 & 21 & $74.76(13.78)$ & -.04 & .97 \\
$2 S D$ & Untreated & 11 & $73.41(16.71)$ & -.13 & .90 & 11 & $75.23(9.65)$ & .12 & .91 \\
\hline \begin{tabular}{l} 
Total sample \\
\hline
\end{tabular} & 96 & $79.32(12.64)$ & 4.07 & $<.01$ & 98 & $74.23(11.99)$ & -.53 & .60 \\
\hline
\end{tabular}

\section{Height Deviation and Treatment Effects on Generic and Chronic-Generic HrQoL}

The two-way MANCOVA for children/adolescents' self-reports yielded no significant multivariate main effects of current height deviation or treatment status. However, a significant effect of the interaction between height deviation and treatment status was found, Pillai's Trace $=.07, F(2,65)=2.51, p=.09, \mathrm{y}_{\mathrm{p}}{ }^{2}=.07$. Subsequent univariate analyses indicated that children/adolescents with current height deviation above $-2 S D$ had better chronic-generic HrQoL when untreated, but children/adolescents with current height deviation equal to or below -2 SD reported better chronic-generic HrQoL when they were treated with GH replacement (see Table 3).

Regarding parents' reports, the two-way MANCOVA showed a significant multivariate main effect of treatment status on paediatric HrQoL, Pillai's Trace $=.09, F(2$, $69)=3.23, p=.05, \mathrm{y}_{\mathrm{p}}{ }^{2}=.09$, indicating that parents reported better HrQoL for treated 
children/adolescents than for untreated children/adolescents. No multivariate main effect of the current height deviation or interaction effects between the two factors on HrQoL were found. Univariate analyses indicated that significant differences in $\mathrm{HrQoL}$ according to treatment status were detected by the DISABKIDS instrument only (see Table 3).

\section{Associations of Socio-demographic and Clinical Variables with HrQoL Scores}

Regression analyses showed no significant associations between socio-demographic or clinical variables and generic HrQoL, both patient and parent reported. Regarding chronicgeneric HrQoL, socio-demographic variables accounted for $8 \%$ of the variance on HrQoL reported by parents, and clinical variables contributed $17 \%$ and $12 \%$ to the explained variance on $\mathrm{HrQoL}$ reported by children/adolescents and by parents, respectively. Specifically, the children/adolescents' male gender was associated with lower parent-reported HrQoL. Being/ have been treated with rhGH replacement was associated with better patientand parent-reported HrQoL (see Table 4). The regression analyses were repeated entering the interaction terms (current height deviation $\mathrm{X}$ diagnosis and current height deviation $\mathrm{X}$ treatment status) in a third block, but no significant additional proportion of HrQoL variance was explained.

\section{Agreement between Patient- and Parent-reports of Paediatric HrQoL}

At an individual level, the examination of the ICC indicated moderate levels of agreement between reports of generic HrQoL as assessed with the KIDSCREEN and strong levels of agreement between reports of chronic-generic HrQoL as assessed by the DISABKIDS instruments (see Table 5). The correlation coefficient found for generic HrQoL was significantly lower than the ICC found for chronic-generic HrQoL. At a group level, the MANCOVA for repeated measures showed no significant multivariate differences between informants, Pillai's Trace $=.03, F(2,65)=.98, p=.38, \mathrm{y}_{\mathrm{p}}{ }^{2}=.03$. Additionally, no significant effects of the interaction between informant and clinical or socio-demographic variables were found. 
Table 3. Main effects and interaction effects of height deviation and treatment on generic and chronic-generic HrQoL.

\begin{tabular}{|c|c|c|c|c|c|c|c|c|c|c|}
\hline & \multicolumn{2}{|c|}{$\begin{array}{c}\text { Current height deviation } \\
\text { above }-2 S D\end{array}$} & \multicolumn{2}{|c|}{$\begin{array}{c}\text { Current height deviation equal } \\
\text { to or below }-2 S D\end{array}$} & \multicolumn{4}{|c|}{ Main effects } & \multirow{2}{*}{\multicolumn{2}{|c|}{$\frac{\text { Interaction effects }}{\text { Height deviation }}$}} \\
\hline & \multirow{3}{*}{$\begin{array}{l}\text { Treated } \\
\boldsymbol{M}(\boldsymbol{S D})\end{array}$} & \multirow{3}{*}{$\begin{array}{c}\text { Untreated } \\
\boldsymbol{M}(\boldsymbol{S D})\end{array}$} & \multirow{3}{*}{$\begin{array}{l}\text { Treated } \\
\boldsymbol{M}(\boldsymbol{S D})\end{array}$} & \multirow{3}{*}{$\begin{array}{c}\text { Untreated } \\
\boldsymbol{M}(\boldsymbol{S D})\end{array}$} & \multirow{2}{*}{\multicolumn{2}{|c|}{ Height deviation }} & \multirow{2}{*}{\multicolumn{2}{|c|}{ Treatment }} & & \\
\hline & & & & & & & & & X Tre & nent \\
\hline & & & & & $F_{(1,66)}$ & $\mathrm{y}_{\mathrm{p}}^{2 \mathrm{a}}$ & $F_{(1,66)}$ & $\eta_{p}^{2 a}$ & $F_{(1,66)}$ & $\eta_{p}^{2 a}$ \\
\hline Patient-reports & $(n=38)$ & $(n=4)$ & $(n=20)$ & $(n=11)$ & & & & & & \\
\hline Generic HrQoL & $79.47(12.91)$ & $81.25(13.31)$ & $80.63(13.56)$ & $73.41(16.71)$ & .67 & .01 & .02 & .00 & 1.29 & .02 \\
\hline Chronic-generic HrQoL & $72.19(21.65)$ & $79.06(18.58)$ & $76.90(15.62)$ & $52.39(21.15)$ & $3.06^{\dagger}$ & .04 & 1.17 & .02 & $4.75^{*}$ & .07 \\
\hline Parent-reports & $(n=40)$ & $(n=5)$ & $(n=21)$ & $(n=11)$ & & & & & & \\
\hline Generic HrQoL & $73.31(12.65)$ & $75.00(10.90)$ & $74.76(13.78)$ & $75.23(9.65)$ & .02 & .00 & .29 & .00 & .07 & .00 \\
\hline Chronic-generic HrQoL & $73.50(20.54)$ & $67.00(20.72)$ & $75.38(16.17)$ & $53.45(16.77)$ & 1.09 & .02 & $4.94^{*}$ & .07 & 1.08 & .02 \\
\hline
\end{tabular}

${ }^{a}$ Effect-size (partial Eta squared) reference values: $\mathrm{\eta}_{\mathrm{p}}{ }^{2} \geq .01=$ small effect, $\mathrm{\eta}_{\mathrm{p}}{ }^{2} \geq .06=$ medium effect and $\mathrm{\eta}_{\mathrm{p}}{ }^{2} \geq .14=$ large effect $($ Cohen, 1988$)$.

${ }^{* * *} p \leq .001$, two-tailed. ${ }^{* *} p \leq .01$, two-tailed. ${ }^{*} p \leq .05$, two-tailed. ${ }^{\dagger} p \leq .10$, two-tailed. 
Table 4. Socio-demographic and clinical variables associated with generic and chronic-generic HrQoL.

\begin{tabular}{|c|c|c|c|c|c|c|c|c|}
\hline & \multicolumn{4}{|c|}{ Patient-reports } & \multicolumn{4}{|c|}{ Parent-reports } \\
\hline & \multicolumn{2}{|c|}{$\begin{array}{c}\text { Generic HrQoL } \\
\boldsymbol{R}^{\mathbf{2}}=\mathbf{. 0 3} ; \boldsymbol{F}_{(\mathbf{5}, \mathbf{6 9 )}}=\mathbf{. 4 5}\end{array}$} & \multicolumn{2}{|c|}{$\begin{array}{l}\text { Chronic-generic HrQoL } \\
\boldsymbol{R}^{\mathbf{2}}=\mathbf{. 1 8} ; \boldsymbol{F}_{(\mathbf{5}, \mathbf{8 0})}=\mathbf{3 . 5 3}^{* *}\end{array}$} & \multicolumn{2}{|c|}{$\begin{array}{c}\text { Generic HrQoL } \\
\boldsymbol{R}^{\mathbf{2}}=\mathbf{. 0 2} ; \boldsymbol{F}_{(\mathbf{5 , 7 1 )}}=\mathbf{. 2 6}\end{array}$} & \multicolumn{2}{|c|}{$\begin{array}{l}\text { Chronic-generic HrQoL } \\
\boldsymbol{R}^{\mathbf{2}}=\mathbf{. 2 0} ; \boldsymbol{F}_{(\mathbf{5}, \mathbf{7 1})}=\mathbf{3 . 4 4}\end{array}$} \\
\hline First step: & \multicolumn{2}{|c|}{$\Delta R^{2}<.01 ; F_{(2,72)}=.13$} & \multicolumn{2}{|c|}{$\Delta R^{2}=.01 ; F_{(2,83)}=.51$} & \multicolumn{2}{|c|}{$\Delta R^{2}=.01 ; F_{(2,74)}=.34$} & \multicolumn{2}{|c|}{$\Delta R^{2}=.08 ; F_{(2,74)}=3.24^{*}$} \\
\hline Socio-demographic variables & $\boldsymbol{\beta}$ & $t$ & $\boldsymbol{\beta}$ & $t$ & $\boldsymbol{\beta}$ & $t$ & $\boldsymbol{\beta}$ & $t$ \\
\hline Gender $^{\text {a }}$ & -.06 & -.50 & -.11 & -1.01 & -.04 & -.31 & -.26 & $-2.30^{*}$ \\
\hline Age group ${ }^{b}$ & -.01 & -.08 & .01 & .03 & .09 & .76 & -.12 & -1.08 \\
\hline Second step: & \multicolumn{2}{|c|}{$\Delta R^{2}=.03 ; F_{(3,69)}=.67$} & \multicolumn{2}{|c|}{$\Delta R^{2}=.17 ; F_{(3,80)}=5.49^{* *}$} & \multicolumn{2}{|c|}{$\Delta R^{2}=.01 ; F_{(3,71)}=.21$} & \multicolumn{2}{|c|}{$\Delta R^{2}=.12 ; F_{(3,71)}=3.37^{*}$} \\
\hline Clinical variables & $\boldsymbol{\beta}$ & $t$ & $\boldsymbol{\beta}$ & $t$ & $\boldsymbol{\beta}$ & $t$ & $\boldsymbol{\beta}$ & $t$ \\
\hline Gender $^{a}$ & -.02 & -.16 & -.04 & -.35 & -.05 & -.42 & -.23 & $-2.10 *$ \\
\hline Age group ${ }^{b}$ & .02 & .14 & .01 & .06 & .08 & .64 & -.09 & -.79 \\
\hline Current height deviation & -.05 & -.37 & .01 & -.04 & .06 & .46 & .16 & 1.41 \\
\hline Diagnosis $^{c}$ & -.13 & -.87 & -.19 & -1.48 & -.08 & -.54 & .17 & 1.24 \\
\hline $\mathrm{GH}_{\text {treatment }}{ }^{\mathrm{d}}$ & .06 & .37 & .27 & $2.02^{*}$ & -.11 & -.69 & .34 & $2.34^{*}$ \\
\hline
\end{tabular}

${ }^{\mathrm{a}}$ Reference group: $0=$ female; ${ }^{\mathrm{b}}$ Reference group: $0=$ children $8-12$ years-old; ${ }^{\mathrm{c}}$ Reference group: $0=$ GHD; ${ }^{\mathrm{d}}$ Reference group: $0=$ untreated.

${ }^{* * *} p \leq .001$, two-tailed. ${ }^{* *} p \leq .01$, two-tailed. ${ }^{*} p \leq .05$, two-tailed. ${ }^{\dagger} p \leq .10$, two-tailed. 
Table 5. Agreement between patient- and parent-reports of generic and chronic-generic HrQoL.

\begin{tabular}{|c|c|c|c|c|c|c|}
\hline & Patient-reports & Parent-reports & & & & \\
\hline & $M(S D)$ & $M(S D)$ & $F_{(1,66)}$ & $\mathrm{y}_{\mathrm{p}}^{2 \mathrm{a}}$ & ICC & $Z$ \\
\hline Generic HrQoL & $78.75(13.35)$ & $74.03(12.25)$ & 1.99 & .03 & $.38^{* * *}$ & \\
\hline Chronic-generic HrQoL & $70.70(21.28)$ & 70.45 (20.09) & .38 & .01 & $.80^{* * *}$ & . \\
\hline
\end{tabular}

\section{Discussion}

The present paper describes the generic and chronic-generic HrQoL of children and adolescents diagnosed with GHD or ISS from five European countries, as compared with the European population norms and between clinical (current height deviation and treatment) groups. It also presents socio-demographic and clinical characteristics associated with HrQoL and agreement between self- and parent-reports of patients' HrQoL. In summary, results indicate that children/adolescents who were diagnosed with GHD or ISS had no significantly lower generic HrQoL compared to the population norms. However, there were differences in chronic-generic HrQoL within the short stature group, depending on current clinical characteristics, namely height deviation and GH treatment groups.

Generic HrQoL of children/adolescents with GHD or ISS was within the population norms for the KIDSCREEN instrument [33], except for the treated patients groups, who reported better HrQoL than the general population, disproving our first hypothesis. These results are consistent with a growing line of research advocating that short stature is not necessarily associated with HrQoL impairments and challenging the view of short stature as a risk factor for positive psychosocial development [20,21]. However, because of its generic nature, the instruments commonly employed in these studies may neglect the impact of physical growth and height development on HrQoL [6]. Studies comparing children/adolescents with short stature to matched control groups of children/adolescents with average height, rather than using population norms, have found significant differences on behavioural, cognitive, emotional and social functioning [23]. For example, a German study using the KINDL as a generic HrQoL instrument in 95 patients with GHD found no differences from the population norms [39], while a US study with 48 patients using the PedsQL instrument found impaired HrQoL in short stature patients compared to a control 
sample of healthy children [40].

In line with our second hypothesis, results also pointed to significant differences in HrQoL within the group of children/adolescents with short stature, on the basis of achieved height and treatment status. Children/adolescents with achieved normal height reported better HrQoL when untreated, while children and adolescents with current height equal to or below $-2 S D$ from the norms reported better HrQoL when they were receiving/ have received GH treatment. A recent review have reported the effectiveness of rhGH treatment for children's growth and improved adult height [41]. However the burden of daily treatments must be balanced with its anticipated benefits. The practical challenges of GH replacement therapy include the need of daily self-injections and frequent medical appointments [22]. While for children/adolescents who have reached normal height since the time of diagnosis the burden of continuing treatment may have a more detrimental than beneficial effect on their HrQoL, children/adolescents who still have significant restrictions in activities of daily living due to short stature may downplay the burden of treatment in view of its anticipated benefits for HrQoL improvement. From the parents' point of view, children/adolescents who were receiving/ have received GH treatment had better HrQoL than those untreated, independent of reached height. These findings suggest that parents tend to minimize the effect of the interaction between the burden of treatments and its efficacy for short-term height gain on their children's HrQoL. Consistently, previous studies show that parents tend to be satisfied with GH treatments and have high expectations about the height that their child would reach in adulthood [26].

The aforementioned differences were not detected with the generic KIDSCREEN instrument but only emerged as significant for the $\mathrm{HrQoL}$ as assessed by the chronic-generic DISABKIDS instrument. The different sensitivity of these two instruments, confirmed in a previous longitudinal study in the context of inpatient rehabilitation for children with chronic conditions [42], reflect the conceptual approach and purposes that guided their development. Thus, a promising avenue to better understand the impact of short stature in the children's and adolescents' physical, psychological and social functioning is the application of HrQoL instruments specifically developed for this condition. Nevertheless, generic instruments are recommended for comparison of patient data with population norms or control samples.

A third set of results confirmed that receiving $\mathrm{GH}$ treatment was significantly associated with better chronic-generic HrQoL, both patient and parent reported, partially supporting our hypothesis. Male gender additionally emerged as significantly associated with poorer HrQoL scores, although only in parents' reports. Neither age group nor current height 
deviation were significantly associated with HrQoL. Many risk factors for failing to promote adaptation to short stature have been described in the literature [28], but most of them are common for average height populations rather than specific for this condition. Nevertheless, social expectations and stereotypes associated with the male gender may assume a particular relevance for their psychosocial development and HrQoL, and the way others interact with the child/adolescent are likely to influence their behaviour and self-esteem $[18,19]$.

Finally, we found moderate and strong levels of agreement between patients' selfreports and parents-reports of generic and chronic-generic HrQoL, respectively. The greater level of agreement found for the chronic-generic measure may be explained by the relevance of the questions for the particular group of children/adolescents with short stature, and the higher likelihood of parents to be more alert to condition-related issues than general aspects of HrQoL [43]. Regarding the hypothesised direction of agreement, parents tended to report lower HrQoL than children/adolescents themselves, particularly for generic HrQoL, although the differences between reports were not statistically significant. A parental underestimation of children's HrQoL as found in our study is consistent with previous research in paediatric populations $[44,45]$. Moreover, the literature has demonstrated that short stature may have a negative influence not only on the child/adolescent, but on the whole family [18] and higher levels of parenting stress were found significant correlated with greater parents' underestimation of children's HrQoL [45].

\section{Limitations and Strengths}

The main limitation of this analysis is the small sample size, which restricts the statistical power to detect small effects, namely interaction effects. The absence of a control group of children/adolescents with average height, but otherwise similar to our group of patients with short stature, must also be mentioned as a limitation, since some authors have referred the importance of using a peer group for paediatric HrQoL comparison instead of population norms [46]. Another limitation is the study's cross-sectional design, which precluded the examination of achieved height and treatment effects over time. Also, treatment effects on HrQoL cannot be inferred because the study is not a randomized clinical trial. An important issue is confounding of diagnosis and treatment status which reflects the regulation for rhGH treatment indication in the participating countries: more GHD patients that ISS patients were rhGH treated. Furthermore, HrQoL in short stature is likely to be affected not only by height and treatments, but also by other clinical variables (e.g., time between the diagnosis of GHD or ISS and the HrQoL assessment, length of treatments, etc.) and 
psychosocial determinants such as coping [6], which were not included or controlled in the present analysis. Finally, social and cultural environment play an important role in adaptation to short stature [28]; however, due to the limited number of participating families in each country, cross-cultural aspects could not be addressed in this study.

Despite these limitations, the present study followed a psychosocial assessment strategy of paediatric HrQoL that relies on incorporating information collected from multiple sources and using instruments characterized by cross-cultural comparability, a modular approach with generic and chronic-generic modules, and an emphasis on positive healthpromoting aspects of $\mathrm{HrQoL}$ [4]. In evaluating HrQoL in short stature youth, the examination of the conjoint influences of clinical and socio-demographic variables on variance in HrQoL ratings is necessary, which was also respected in the design of the research presented in this paper.

\section{Conclusions and Future Directions}

Results presented additional evidence on the importance of clinical characteristics, namely rhGH treatment status and achieved height, for paediatric HrQoL. However, short stature is not necessarily experienced by children/adolescents and by their parents as a disabling condition [20]. If HrQoL improvement is an important goal for GH treatments, resource allocation in paediatric endocrinology should balance the effectiveness of $\mathrm{GH}$ treatments for growth velocity, increased adult height and enhanced psychosocial functioning with the financial costs and the potential burden for children/adolescents and families $[9,17]$. Identifying the patients and the circumstances under which the GH treatment may be most effective calls for an adequate assessment of HrQoL [20]. As our results suggest, generic measures may be less sensitive in detecting small but clinically relevant differences in HrQoL than are chronic-generic measures. In order to better evaluate the effectiveness of interventions, reliable, cross-cultural and developmentally appropriate condition-specific instruments for assessing HrQoL in paediatric short stature, such as the QoLISSY instrument, are needed [35]. So far the use of different HrQoL instruments in paediatric short stature has impeded the health economic assessment of rhGH treatment benefits. Studies assessing costbenefit in terms of HrQoL have reported large variations of costs for quality-adjusted life years (QALYs) gained [47-51].

In addition to or independent from rhGH treatment, psychosocial interventions to support the adaptation process to short stature have been recommended [52]. These include psychological interventions focused on promoting individual coping resources and social 
action aiming to reduce height-related stereotypes and social exclusion [6,9]. Future longitudinal research addressing the processes underlying outcomes of adaptation in paediatric short stature should also study whether psychosocial interventions might increase resilience in children/adolescents and contribute to their HrQoL. Given the central role of social environment for children/adolescents' adaptation to short stature, cross-cultural studies examining the impact of different height-related social attitudes on children/adolescents' selfconcept, height satisfaction, social integration and overall $\mathrm{HrQoL}$ are needed.

\section{Key issues:}

1. Health-related quality of life is an important patient-reported outcome in paediatric endocrinology which should be obtained by young patients and supplemented by parents.

2. Studies investigating HrQoL impairments in short statured children and adolescents yield inconsistent results as regards comparison to population norms/ healthy controls and across patient clinical characteristics.

3. HrQoL assessment in young patients with short stature profits from a modular approach, including generic, chronic-generic and condition-specific instruments, the latter of which have only recently been developed.

4. Generic instruments may underestimate the patient's burden, while chronic-generic measures may detect more subtle impairments on the basis of clinical and sociodemographic characteristics.

5. Analysis of the cross-sectional data suggests better HrQoL for rhGH-treated patients with current height equal to or below $-2 S D$ as compared to children who have achieved normal height.

6. The variability in HrQoL of short statured children/adolescents is better explained by rhGH treatment status than by patients' developmental characteristics.

7. Patient's and parent's HrQoL ratings diverged, with parents observing poorer HrQoL as compared to patient self-assessments.

8. Psychosocial interventions may be helpful to improve adaptation and consequently HrQoL of patients but programmes need to be developed, implemented and evaluated. 


\section{Acknowledgments}

This study is part of the "Quality of Life in Short Stature Youth" (QoLISSY) project, a joint initiative between the University Medical Centre Hamburg-Eppendorf and ${ }^{\circledR}$ Pfizer Limited. The QoLISSY study group, in addition to the German team of Monika Bullinger, Julia Quitmann and Anja Rohenkohl (University Medical Centre Hamburg- Eppendorf, Department of Medical Psychology, Hamburg, Germany), includes John E. Chaplin (Sahlgrenska Academy at University of Gothenburg, Department of Paediatrics, Växthuset, Queen Silvia's Children's Hospital, Gothenburg, Sweden), Michael Herdman (IMIM University, Insight Consulting and Research, Barcelona, Spain), Emmanuelle Mimoun (University of Toulouse, Department of Pediatric Endocrinology, Toulouse, France), Kendra DeBusk (University of Edinburgh, Department of Clinical Psychology, Edinburgh, Scotland), Eva Feigerlova (University of Toulouse, Department of Pediatric Endocrinology, Toulouse, France), Carolina Lunde (Sahlgrenska Academy at University of Gothenburg, Department of Pediatrics, Växthuset, Queen Silvia's Children's Hospital, Gothenburg, Sweden), Maria Dellenmark-Blom (Sahlgrenska Academy at University of Gothenburg, Department of Pediatrics, Växthuset, Queen Silvia’s Children's Hospital, Gothenburg, Sweden), Dolores Sanz (IMIM University, Insight Consulting and Research, Barcelona, Spain), Andreas Pleil (Pfizer, Inc. Specialty Care MDG, Outcomes Research, San Diego, CA), Hartmut Wollmann (Pfizer Ltd., Specialty Care MDG, Endocrinology, Walton Oaks, UK) and Michael Power (University of Edinburgh, Department of Clinical Psychology, Edinburgh, Scotland).

\section{Financial \& competing interests' disclosure}

The development of the QoLISSY questionnaire was funded through a research grant by Pfizer Ltd. MB has received honoraria and acted as consultant. AP and HW (members of the QoLISSY group) are Pfizer Employees. All other authors have no involvement with Pfizer ltd. nor have financial interests. This includes employment, consultancies, honoraria, stock ownership or options, expert testimony, grants or patents received or pending, or royalties.

NS was supported by a PhD Grant from the Portuguese Foundation for Science and Technology (SFRH/BD/69885/2010).

No writing assistance was utilized in the production of this manuscript. 


\section{References}

Papers of particular interest are identified as:

* of interest

** of considerable interest

1. Matza LS, Swensen AR, Flood EM, Secnik K, Leidy NK. Assessment of healthrelated quality of life in children: a review of conceptual, methodological, and regulatory issues. Value in Health, 7(1), 79-92 (2004).

2. Ravens-Sieberer U, Ellert U, Erhart M. Gesundheitsbezogene lebensqualitat von kindern und jugendlichen in Deutschland. Eine normstichprobe fur Deutschland aus dem kinder- und jugendgesundheitssurvey (KIGGS). Bundesgesundheitsblatt, Gesundheitsforschung, Gesundheitsschutz, 50(5-6), 810-818 (2007).

3. World Health Organization. Measurement of quality of life in children: report of WHO/ IACAPAP working party, London, UK (1993).

** Guidelines for assessing quality of life in children, with particular focus on instrument development and use.

4. Bullinger M, Schmidt S, Petersen C, Erhart M, Ravens-Sieberer U. Methodische herausforderungen und potentiale der evaluation gesundheitsbezogener lebensqualitat fur kinder mit chronischen erkrankungen im medizinischen versorgungssystem. Medizinische klinik, 102(9), 734-745 (2007).

5. Brütt AL, Sandberg DE, Chaplin J et al. Assessment of health-related quality of life and patient satisfaction in children and adolescents with growth hormone deficiency or idiopathic short stature - part 1: a critical evaluation of available tools. Hormone research, 72(2), 65-73 (2009).

6. Bullinger M, Koltowska-Haggstrom M, Sandberg D et al. Health-related quality of life of children and adolescents with growth hormone deficiency or idiopathic short stature - part 2: available results and future directions. Hormone research, 72(2), 7481 (2009).

** Literature review on the impact of pediatric short stature in children's healthrelated quality of life. Noteworthy that methodological limitations of current research and future directions were discussed.

7. Richmond EJ, Rogol AD. Growth hormone deficiency in children. Pituitary, 11(2), 115-120 (2008).

8. GH Research Society. Consensus guidelines for the diagnosis and treatment of growth hormone $(\mathrm{GH})$ deficiency in childhood and adolescence: summary statement of the 
GH Research Society. GH Research Society. The Journal of clinical endocrinology and metabolism, 85(11), 3990- 3993 (2000).

9. Cohen P, Rogol AD, Deal CL et al. Consensus statement on the diagnosis and treatment of children with idiopathic short stature: a summary of the Growth Hormone Research Society, the Lawson Wilkins Pediatric Endocrine Society, and the European Society for Paediatric Endocrinology Workshop. The Journal of clinical endocrinology and metabolism, 93(11), 4210-4217 (2008).

10. Batty GD, Shipley MJ, Gunnell D et al. Height, wealth, and health: an overview with new data from three longitudinal studies. Economics and human biology, 7(2), 137152 (2009).

11. Peck MN, Lundberg O. Short stature as an effect of economic and social conditions in childhood. Social science \& medicine, 41(5), 733-738 (1995).

12. Lindsay R, Feldkamp M, Harris D, Robertson J, Rallison M. Utah Growth Study: Growth standards and the prevalence of growth hormone deficiency. J Pediatr. , 25(1), 29-35 (1994).

13. Ranke MB. Towards a consensus on the definition of idiopathic short stature. Hormone research, 45(suppl 2), 64-66 (1996).

14. Wit JM, Clayton PE, Rogol AD, Savage MO, Saenger PH, Cohen P. Idiopathic short stature: definition, epidemiology, and diagnostic evaluation. Growth hormone \& IGF research: official journal of the Growth Hormone Research Society and the International IGF Research Society, 18(2), 89-110 (2008).

15. Tanaka T, Cohen P, E. Clayton P, Laron Z, L. Hintz R, C. Sizonenko P. Diagnosis and management of growth hormone deficiency in childhood and adolescence - Part 2: Growth hormone treatment in growth hormone deficient children. Growth Hormone \& IGF Research, 12(5), 323-341 (2002).

16. Wit JM, Reiter EO, Ross JL, Saenger PH, Savage MO, Rogol AD, Cohen P. Idiopathic short stature: management and growth hormone treatment. Growth Hormone \& IGF Researc, 18(2), 111-135 (2008).

17. Bryant J, Baxter L, Cave CB, Milne R. Recombinant growth hormone for idiopathic short stature in children and adolescents (Review). Cochrane Database of Systematic Reviews, 18(3), 1-30 (2007).

18. Sandberg DE, Voss LD. The psychosocial consequences of short stature: a review of the evidence. Best Practice \& Research Clinical Endocrinology \& Metabolism, 6(3), 449-463 (2002). 
* Literature review focused on the psychological adaptation of short statured children and adolescents. This paper highlights the need of including non-auxological factors in clinical decision making.

19. Voss LD, Mulligan J. Bullying in school: are short pupils at risk? Questionnaire study in a cohort. British Medical Journal, 320(7235), 612-613 (2000).

20. Sandberg DE, Colsman M. Growth hormone treatment of short stature: status of the quality of life rationale. Hormone research, 63(6), 275-283 (2005).

21. Visser-van Balen H, Geenen R, Kamp GA, Huisman J, Wit JM, Sinnema G. Longterm psychosocial consequences of hormone treatment for short stature. Acta Paediatrica, 96(5), 715-719 (2007).

22. Sheppard L, Eiser C, Davies HA et al. The effects of growth hormone treatment on health-related quality of life in children. Hormone research, 65(5), 243-249 (2006).

** Longitudinal study demonstrating the effects of growth hormone treatment on quality of life improvement.

23. Wheeler PG, Bresnahan K, Shephard BA, Lau J, Balk EM. Short stature and functional impairment: a systematic review. Archives of Disease in Childhood 158(3), 236-243 (2004).

24. Ross JL, Sandberg DE, Rose SR et al. Psychological adaptation in children with idiopathic short stature treated with growth hormone or placebo. The Journal of clinical endocrinology and metabolism, 89(10), 4873-4878 (2004).

25. Theunissen NC, Kamp GA, Koopman HM, Zwinderman KA, Vogels T, Wit JM. Quality of life and self-esteem in children treated for idiopathic short stature. The Journal of Pediatrics, 140(5), 507-515 (2002).

26. Rekers-Mombarg LTM, Busschbach JVV, Massa GG, Dicke J, Wit JM, Dutch Growth Hormone Working Group. Quality of life of young adults with idiopathic short stature: effect of growth hormone treatment. Acta Paediatrica, 87(8), 865-870 (1998).

27. Leiberman E, Pilpel D, Carel CA, Levi E, Zadik Z. Coping and satisfaction with growth hormone treatment among short-stature children. Hormone research, 40(4), 128-135 (1993).

28. Visser-van Balen H, Sinnema G, Geenen R. Growing up with idiopathic short stature: psychosocial development and hormone treatment: a critical review. Archives of Disease in Childhood, 91(5), 433-439 (2006).

** Literature review on the risk and protective factors that affect psychosocial 
adaptation of children with short stature.

29. Guyatt GH. A taxonomy of health status instruments. The Journal of Rheumatology, 22(6), 1188-1190 (1995).

* Discussion of advantages and disadvantages of using generic or disease-specific instruments for assessing health-related quality of life.

30. Bullinger M. Health related quality of life and subjective health: Overview of the status of research for new evaluation criteria in medicine. Psychotherapie, Psychosomatik, medizinische Psychologie, 47(3-4), 76-91 (1997).

31. Wiebe S, Guyatt G, Weaver B, Matijevic S, Sidwell C. Comparitive responsiveness of generic and specific quality-of-life instruments. Journal of clinical epidemiology, 56, 52-60 (2003).

32. Holden EW, Chmielewski D, Nelson CC, Kager VA. Controlling for general and disease-specific effects in child and family adjustment to chronic childhood illness. Journal of Pediatric Psychology, 22(1), 15-27 (1997).

33. The KIDSCREEN Group Europe. The KIDSCREEN questionnaires: Quality of life for children and adolescents - Handbook, Pabst Science Publishers, Lengerich (2006).

34. The DISABKIDS Group Europe. The DISABKIDS questionnaires: Quality of life questionnaires for children with chronic conditions - Handbook, Pabst Science Publishers, Lengerich (2006).

35. Bullinger M, Quitmann J, Power M, Herdman M, Mimoun E, Debusk K, Feigerlova E, Lunde C, Dellenmark-Blom M, Sanz D, Rohenkohl A, Pleil A, Wollmann H, Chaplin JE. Assessing the quality of life of health-referred children and adolescents with short stature: development and psychometric testing of the QoLISSY instrument. Health Qual Life Outcomes, 11, 76 (2013).

36. Cohen J. Statistical power analysis for the behavioral sciences, Lawrence Erlbaum Associates Inc., Hillsdale (1988).

37. Sneeuw KC, Sprangers MA, Aaronson NK. The role of health care providers and significant others in evaluating the quality of life of patients with chronic disease. Journal of clinical epidemiology, 55, 1130-1143 (2002).

38. Preacher K. Calculation for the test of the difference between two independent correlation coefficients. http://quantpsy.org (Accessed July 2012).

39. Geisler A, Lass N, Reinsch N et al. Quality of life in children and adolescents with growth hormone deficiency: association with growth hormone treatment. Hormone Research in Paediatrics, 78(2), 94-99 (2012). 
40. Stephen MD, Varni JW, Limbers CA, Yafi M, Heptulla RA, Renukuntla VS, Bell CS, Brosnan PG. Health-related quality of life and cognitive functioning in pediatric short stature: comparison of growth-hormone-naive, growth-hormone-treated, and healthy samples. European journal of pediatrics, 170(3), 351-358 (2011).

41. Takeda A, Cooper K, Bird A, Baxter L, Frampton GK, Gospodarevskaya E, Welch K, Bryant J. Recombinant human growth hormone for the treatment of growth disorders in children: a systematic review and economic evaluation. Health technology assessment, 14(42), 1-209 (2010).

42. Gustke M, Kosiol D, Bauer CP, Baumann A, Stachow R, Farin E. Die fragebögen Disabkids und Kidscreen - vergleich der änderungssensitivität bei der erfassung gesundheitsbezogener lebensqualität von kindern und jugendlichen. Zeitschrift für Medizinische Psychologie, 20(2), 51-59 (2011).

43. Upton P, Lawford J, Eiser C. Parent-child agreement across child health-related quality of life instruments: a review of the literature. Quality of life research, 17, 895913 (2008).

* Literature review addressing the extent and direction of agreement between children's and parents' reports of health-related quality of life and the factors affecting the levels of agreement.

44. Sattoe J, van Staa A, Moll H, On Your Own Feet Research Group.The proxy problem anatomized: child-parent disagreement in health related quality of life reports of chronically ill adolescents. Health and Quality of Life Outcomes, 10, 10-22 (2012).

45. White-Koning M, Arnaud C, Dickinson HO, Thyen U, Beckung E, Fauconnier J, McManus V, Michelsen SI, Parkes J, Parkinson K, Schirripa G, Colver A. Determinants of child-parent agreement in quality-of-life reports: a European study of children with cerebral palsy. Pediatrics, 120, e804-e814 (2007).

46. Gerharz EW, Eiser C, Woodhouse CRJ. Current approaches to assessing the quality of life in children and adolescents. BJU International, 91, 150-154 (2003).

47. Christensen T, Buckland A, Bentley A, Djurhuus C, Baker-Searle R. Costeffectiveness of somatropin for the treatment of short children born small for gestational age. Clinical therapeutics, 32(6), 1068-1082 (2010).

48. Durand-Zaleski I. Developments in idiopathic short stature: cost versus allocation of resources. Hormone Research in Paediatrics, 76(3), 33-35 (2011).

49. Radcliffe DJ, Pliskin JS, Silvers JB, Cuttler L. Growth hormone therapy and quality of life in adults and children. Pharmacoeconomics, 22(8), 499-524 (2004). 
50. Rosenfeld RG. Pharmacological interventions for short stature: pros and cons. Nestlé Nutrition Institute Workshop Series, 71, 207-217 (2013).

51. Ranke MB. Treatment of children and adolescents with idiopathic short stature. Nature Reviews Endocrinology, 9(6), 325-340 (2013).

52. Noeker M. Management of idiopathic short stature: psychological endpoints, assessment strategies and cognitive-behavioral intervention. Hormone research, 71 Suppl 1, 75-81 (2009). 